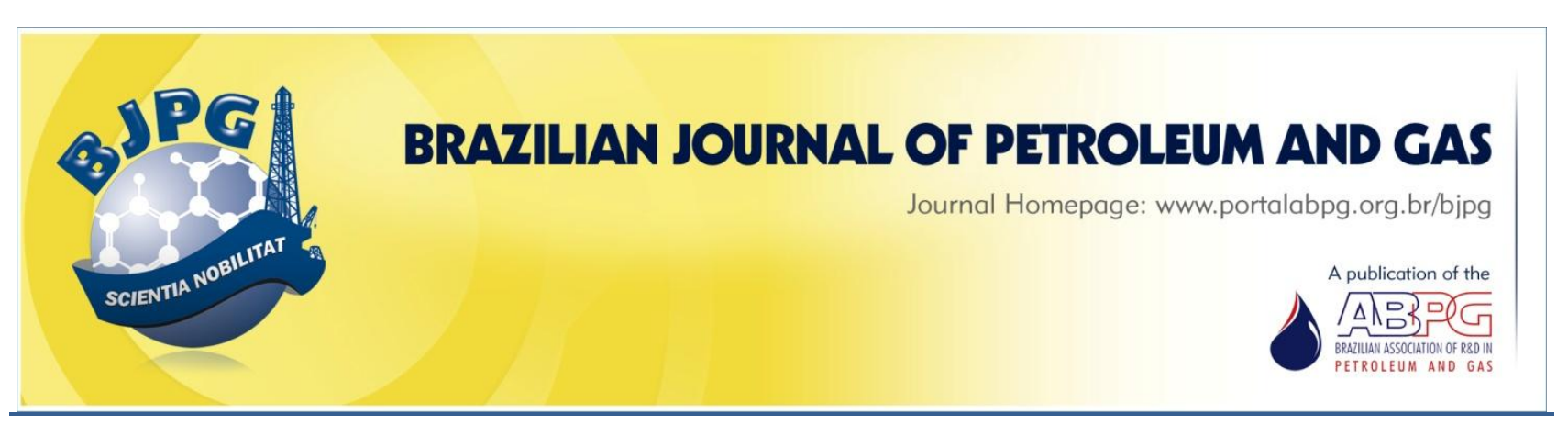

\title{
THE INFLUENCE OF SALT DOMES IN DRILLING WELL ACTIVITIES
}

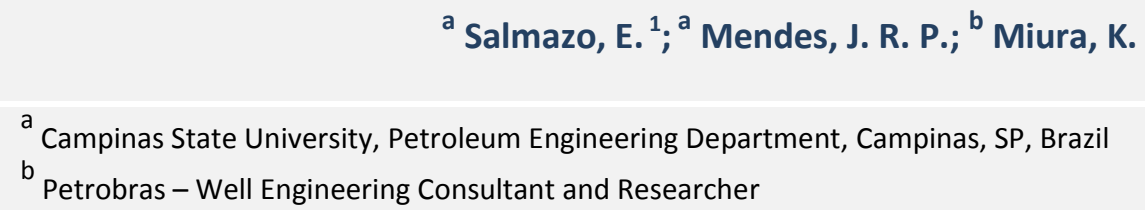

\section{ABSTRACT}

The present work discusses the challenges associated with the drilling activities in oil wells through formations affected by the presence of salt domes. These geological structures can induce large stresses in the underlying and adjacent formations, requiring the development of specific planning for drilling and maintenance of such oil wells. During drilling, due to the presence of salt, numerous reports of problems such as stuck pipe, salt dissolution, forming mechanical stops and caves arise. More specific difficulties can occur in formations around a salt dome, related to the changes in the stress field, which include problems of well instability and abnormality of pressure zones. After casing, issues involving collapsing casestructures can take place. To prevent and mitigate risks associated to this activity, it is crucial to understand the physical phenomena behind it. With such finality, the present work studies problems related to such physical mechanisms, for instance, hydrodynamic instability, more specifically, the Rayleigh-Taylor (RT) instability. This study led to the development of an analytical model to predict salt dome formation. It discusses the ways in which it can interfere positively in parameters related to the drilling activity as, for example, the tension field in the formation around the salt dome.

\section{KEYWORDS}

petroleum; salt domes; creep; Rayleigh-Taylor instability; well drilling

\footnotetext{
${ }^{1}$ To whom all correspondence should be addressed.

Address: Petroleum Engineering Department, Campinas State University, Mendeleyev Street 200, Cidade Universitária Zeferino Vaz, Campinas - São Paulo - Brazil, Zip code 13083-860

Telephone / Fax: +55 19 3521-3339/+55 19 3829-4999| E-mail: esalmazo@dep.fem.unicamp.br doi:10.5419/bjpg2013-0004
} 


\section{INTRODUCTION}

Salt formations are of great importance to the petroleum industry. The relevance of these saline formations reside in their low permeability and large deformation capability characteristics. These qualities allow them to form great structural oil traps and, consequently, associated to the formation of good oil reservoirs.

However, these same characteristics which make great retaining evaporitic rocks may also present big challenges related to exploration activity in their vicinity. Evaporite rocks present great mobility when submitted to large deviatoric tensions and elevated temperatures, in a behavior known as creep. During the drilling phase, numerous reports of problems occur. These issues involve well closing, drill column entrapment and the creation of mechanical stops, and caves by salt dissolution by drilling fluid. From a long-term viewpoint, when buried, evaporite rocks keep their density nearly constant but, with the increase in overburden stress and temperature, the salts start to creep.

Because the upper formation tends to present higher densities than the salt formations, this creep behavior leads to the phenomenon of inversion of fluids, governed by the RT hydrodynamic instability mechanism. The salt tends to pierce the adjacent layers creating structures known as salt domes.

According to Jackson's study (Jackson et al., 1995) the evolution of salt tectonic models can be separated into three ages. The age of pioneer works, that was started in 1856 with the Ville publication. In this age, the works relied, basically, on field results obtained in North Africa and North of Persian Gulf. Stille (1925) had proposed a model in which the salt, due to its mobility, only molded to shapes imposed by other structures. Barton (1933) argued that the growth of a diapir occurs due to subsidence of embasement; the salt, thus, remains only near the surface. This model was named downbuilding. These works considered that the evolution of a diapir occurs in a passive way, since the salt does not exert influence over the formation around it.

The age of fluid model, according to Mohriak and Szatmari (2008), is marked by the predominance of concepts that link the diapirs with salt creep, when the later is under great geostatic
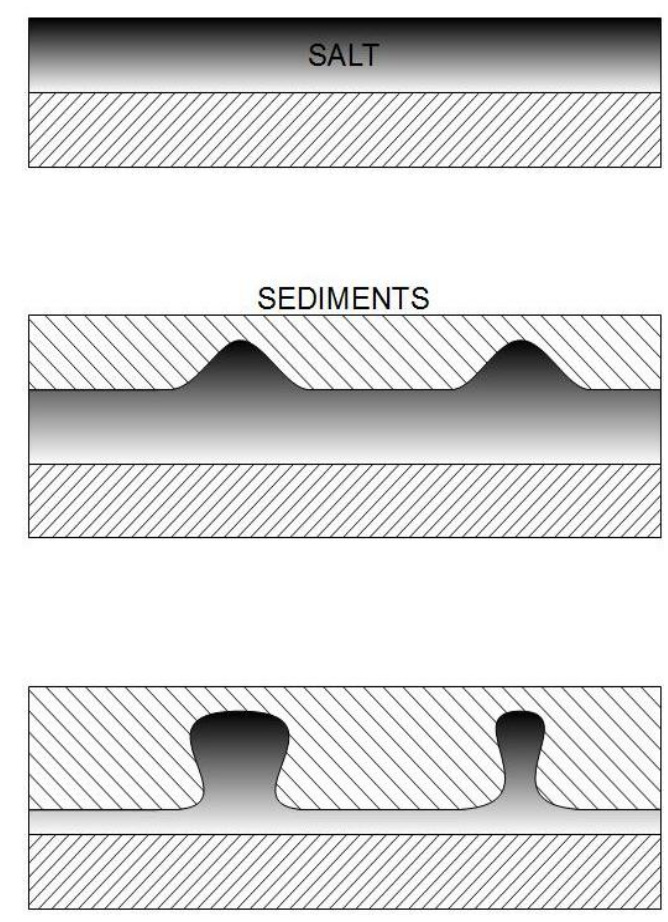

Figure 1. The salt piercing. At a first stage the salt is deposited and, then, buried by sediments. The increase in the overburden over the salt layer causes it to exhibit creep and, due to its low density, to start piercing the sediments above.

pressures. They present a behavior that is similar to the one of a lighter fluid when immersed in a heavier fluid. The overburden stress and the changes in density and viscosity between salt and other rocks were the main factors causing the diapirism. Such model is called active diapirism, because it considers that a diapir is formed by the buoyancy force only, deforming and breaking formations above, as shown in Figure 1.

Biot and Odé (1965) had developed an analytical model to determine the growth rate of a salt dome in its early stage. In this work, these authors even consider effects like compaction and mass redistribution over the free surface.

The third age, the age of extensional tectonics, has it start point with the publications of Vendeville and Jackson (1992). The authors considered that diapirs grow in thin-skinned regions, where faults caused by extensional efforts are present. Considering that the buoyancy force by itself would not be sufficient to cause deformation and fracture in the over layer of brittle rocks, it would prevent the growth of a diapir. In that sense, salt would occupy the spaces left by the 
faults. This model was called reactive. Schultz-ela et al.(1993) performed simulations to demonstrate that only the force due to density contrast was not enough to start the piercement, relying on mechanisms like faults and/or differential loading.

Poliakov et al. (1996) developed a numerical model in which are taken into account both buoyancy and faulting effects. His work lists cases where the diapirism may be associated with each mechanism and case, where both are acting together.

Therefore, this work is based on the premise that there is a consensus involving the formation of a diapir, in a direct or indirect way, and the buoyancy force due to density contrasts between the evaporitic rock and sediments above. An important mechanism that guides the diapir evolution is, therefore, strongly related to the hydrodynamic instability, specifically, the one which was described by Rayleigh (1883) and Taylor (1950).

In this present work, an analytical model is developed to predict the stress induced by the salt piercement in the formation surrounding a diaper. It will also discuss the influence of salt piercement in well-drilling activity.

\section{METHODS}

This work started on the premise that both salt rocks and sedimentary rocks above the salt, behave, in a geological time scale, as fluids flowing. Therefore, one can use an analytical model of fluid flow, in quasi-static regime, within hydrodynamic instability theory, to determine the velocity field of the salt layer. This starting point also allows one to verify the stress field in the region of separation from the pallets immediately above. From the stress field induced by the salt piercing, it is possible to estimate parameters like pore pressure, fracture gradient, and principal directions, to assist in the decision-making process.

As an example, the obtained equation was applied in a Campos Basin case. In the case in exam several kicks happened during drilling near a salt dome. This particular case occurred in a $200 \mathrm{~m}$ water depth.

\subsection{Analytical model of a salt dome temporal evolution}

For long time periods, the layers of sediments under deviatoric stress may be considered like newtonian fluids, flowing slowly. In this sense, it is possible to apply a newtonian fluid model to describe the tension field.

The Navier-Stokes equations were used for a system under quasi-static conditions, with velocities components $u_{1}, u_{2}$, and $u_{3}$. Where the inertial effects are neglected $\left(\frac{D u_{1}}{D t}=\frac{D u_{2}}{D t}=\frac{D u_{3}}{D t}=0\right)$, assuming the form:

$$
\left\{\begin{array}{l}
\frac{D u_{1}}{D t}=\frac{\partial u_{1}}{\partial t}+\left(u_{i} \frac{\partial u_{1}}{\partial x_{i}}\right)=-\frac{1}{\rho} \frac{\partial P}{\partial x_{1}}+\mu \frac{1}{\rho} \nabla^{2} u_{1}=0 \\
\frac{D u_{2}}{D t}=\frac{\partial u_{2}}{\partial t}+\left(u_{i} \frac{\partial u_{2}}{\partial x_{i}}\right)=-\frac{1}{\rho} \frac{\partial P}{\partial x_{2}}+\mu \frac{1}{\rho} \nabla^{2} u_{2}=0 \\
\frac{D u_{3}}{D t}=\frac{\partial u_{3}}{\partial t}+\left(u_{i} \frac{\partial u_{3}}{\partial x_{i}}\right)=-\frac{1}{\rho} \frac{\partial P}{\partial x_{3}}+\mu \frac{1}{\rho} \nabla^{2} u_{3}=0
\end{array}\right.
$$

Where, $P=p-\rho g z ; p$ is the pressure; $g$ is the gravity; $\rho$ is the fluid density; and $\mu$ its viscosity.

In the bi dimensional case $\left(x_{1} \equiv x\right.$ and $\left.x_{3} \equiv z\right)$ it is possible to define a scalar stream function $\psi(x, z)$ - from now on represented just by $\psi$, such that $u=-\frac{\partial \psi}{\partial z}$ and $w=\frac{\partial \psi}{\partial x}$, where $u$ and $w$ are the components of fluid flow velocity which respect to $x$ e $z$ directions, respectively. Being $\psi$ a continuous function, the previous relations satisfy automatically the relation of continuity $\operatorname{div}(\vec{U})=\frac{\partial u}{\partial x}+\frac{\partial w}{\partial z}=0$

The stream function $\psi=c t e$ describes the streamlines of flow, whose vectors $\vec{U}(\vec{x})=(u(\vec{x}), w(\vec{x}))$ are tangents in which point and, in a steady flow, coincides with the trajectory of each fluid particle.

Using the stream function $\psi$ in the Equations 1 above, for a bi dimensional flow, one obtains: 


$$
\begin{cases}\frac{\partial P}{\partial x}+\mu \nabla^{2} \frac{\partial \psi}{\partial z}= & 0 \\ -\frac{\partial P}{\partial z}+\mu \nabla^{2} \frac{\partial \psi}{\partial x}= & 0\end{cases}
$$

Differentiating the first equation with respect to $z$ and the second with respect to $x$ :

$$
\left\{\begin{array}{l}
\frac{\partial P}{\partial z \partial x}+\mu \frac{\partial}{\partial z} \nabla^{2} \frac{\partial \psi}{\partial z}=0 \\
-\frac{\partial P}{\partial x \partial z}+\mu \frac{\partial}{\partial x} \nabla^{2} \frac{\partial \psi}{\partial x}=0
\end{array}\right.
$$

Where the function $P$ is continuous, one has from Clairau theorem that $\frac{\partial \psi}{\partial z \partial x}=\frac{\partial \psi}{\partial x \partial z}$, adding the Equations ( 3 ) the bi harmonic equation it can be found:

$$
\frac{\partial^{4} \psi}{\partial x^{4}}+2 \frac{\partial^{4} \psi}{\partial x \partial z}+\frac{\partial^{4} \psi}{\partial z^{4}}=\nabla^{4} \psi=0
$$

\subsection{Two layers of same thickness}

Applying the Equation 4 in a fluid system of different densities $\rho_{1}$ e $\rho_{2}$, and different viscosities $\mu_{1}$ e $\mu_{2}$, in an arrange of vertical strata, as shown in Figure 2, where $h$ is the thickness of each layer, and based on linear hydrodynamic instability theory, one could develop a mathematical model for the temporal evolution of small harmonic perturbations to this system.

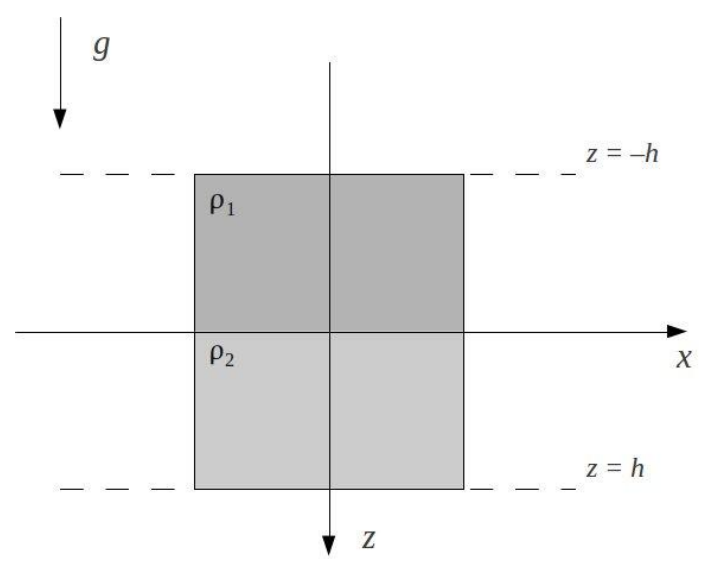

Figure 2. Fluid arrange.
In this case, the bi harmonic equation has the following solution:

$$
\begin{array}{r}
\psi(x, z, t)=\sin \left(k x+\varphi_{0}\right)(A \cosh (k z)+B \sinh (k z)+ \\
+z C \cosh (k z)+z D \sinh (k z))
\end{array}
$$

The development to obtain the Equation 5 may be found in Turcotte and Schumbert (1982). A similar model, but more comprehensive, was developed by Biot (1963a) and Biot (1963b).

The parameter $k$, the wave number of the perturbation, and the phase $\varphi_{0}$ are determined by the boundary conditions of the problem, as the constants $A, B, C$, and $D$, but these ones present time dependence, since they represent the amplitude of the perturbation.

The stream function describes the streamlines of fluid flow, in this case the streamlines of salt layer and, consequently, the streamlines of sediments on the separation interface between both of them. The constants of integration may be found using appropriated boundary conditions. Being $\psi_{1}$ and $\psi_{2}$ the stream functions for the sediments and for the salt layer respectively, then the boundary conditions to be imposed are:

1. Continuity conditions at the separation surface, i.e., the velocity components of both fluids must be equal at $z=0$. So, $w_{1}=\frac{\partial \psi_{1}}{\partial x}=\frac{\partial \psi_{2}}{\partial x}=w_{2}$ and $u_{1}=-\frac{\partial \psi_{1}}{\partial z}=-\frac{\partial \psi_{2}}{\partial z}=u_{2}$

2. No slip conditions at upper and bottom boundary $z= \pm h$, i.e., $u_{1}=w_{1}=0$ at $z=-h$ and $u_{2}=w_{2}=0$ at $z=h$;

3. Shear stress must be continuous across the interface between the fluid layers which implies $\mu_{1}\left(\frac{\partial u_{1}}{\partial z}+\frac{\partial w_{1}}{\partial x}\right)=\mu_{2}\left(\frac{\partial u_{2}}{\partial z}+\frac{\partial w_{2}}{\partial x}\right)$ at $z=0$;

4. The buoyancy force per unit area at the surface between the fluids, due to displacement, $\eta$, must be balanced only by the pressure difference $\left(\rho_{1}-\rho_{2}\right) g \eta=\left(P_{2}-P_{1}\right)_{z=0}$.

Applying these boundary conditions, one may find the final forms for the stream functions $\psi_{1}$ and $\psi_{2}$. These functions will describe, at the separation 
surface $(z=0)$, the surface form $\eta(x, z, t=0)$, because the ascent speed in any point of this surface must be equal to the time rate change of the surface, so it can be written:

$\frac{\partial \eta}{\partial t}=\left(\frac{\partial \psi}{\partial x}\right)_{z=0}$

Which determines the vertical growth rate of a diapir in any point $x$. The solution of the differential equation above can be easily evaluated by variable separation and has the form:

$\eta(x, t)=\eta(x, t=0) e^{\left(t / \tau_{a}\right)}$

Where:

$$
\begin{array}{r}
\tau_{a}=-\frac{2 k}{g\left(\mu_{1}+\mu_{2}\right)\left(\rho_{1}-\rho_{2}\right)} \times \\
\times\left(\mu_{1}^{2}+4 \mathrm{~h}^{2} \mathrm{k}^{2} \mu_{1}^{2}+2 \mu_{1} \mu_{2}+24 \mathrm{~h}^{2} \mathrm{k}^{2} \mu_{2} \mu_{1}+\right. \\
+\mu_{2}^{2}+4 \mathrm{~h}^{2} \mathrm{k}^{2} \mu_{2}^{2}+4 \mathrm{~h}^{2} \mathrm{k}^{2}\left(\mu_{1}-\mu_{2}\right)^{2} \operatorname{Cosh}[2 \mathrm{hk}]- \\
\left.-\left(\mu_{1}+\mu_{2}\right)^{2} \operatorname{Cosh}[4 h k]\right) \\
\times\left(4 h k+8 h^{3} k^{3}-4 h k \operatorname{Cosh}[2 h k]-\right. \\
\left.-2\left(1+2 h^{2} k^{2}\right) \operatorname{Sinh}[2 h k]+\operatorname{Sinh}[4 h k]\right)^{-1}
\end{array}
$$

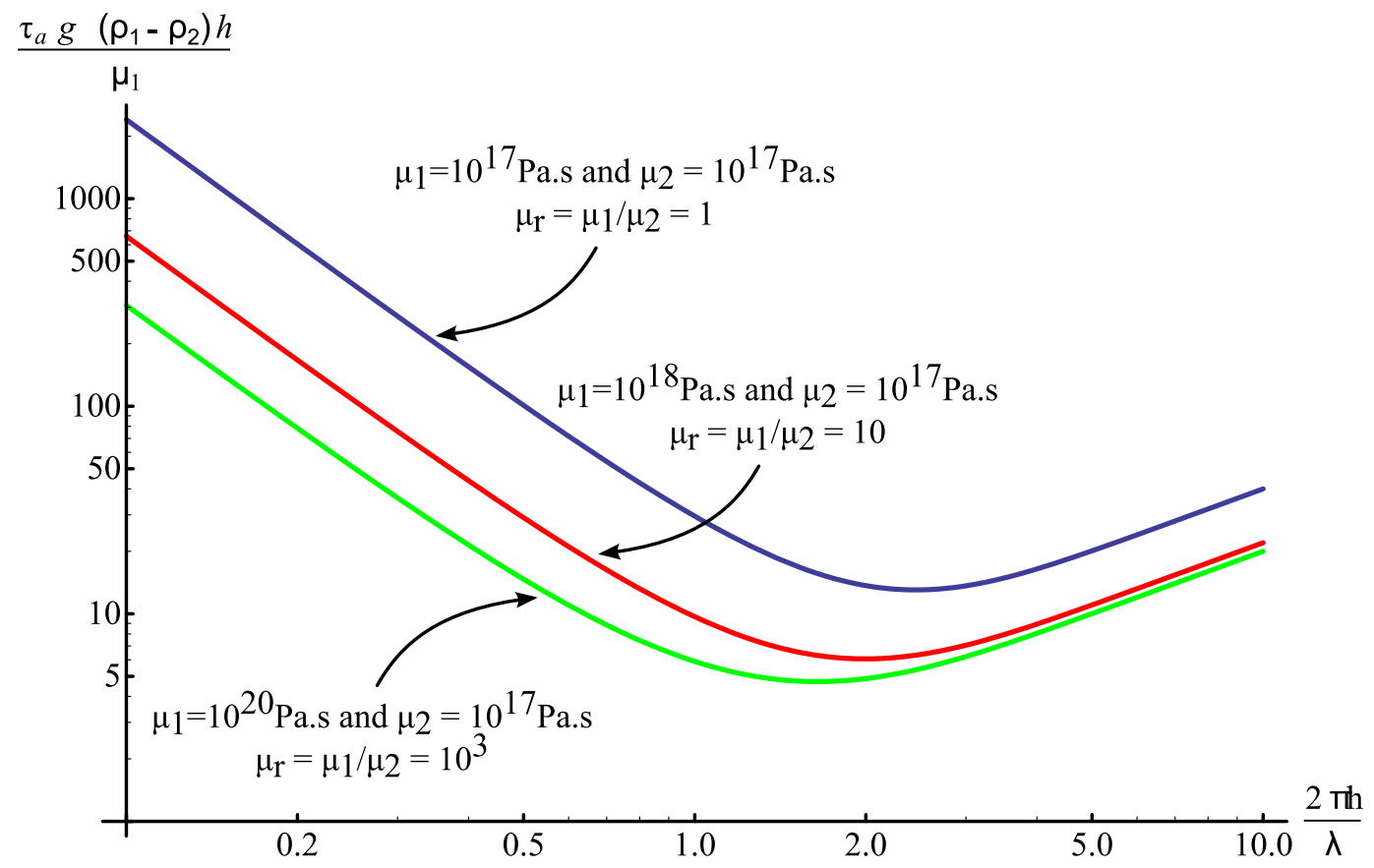

Figure 3. Dimensionless parameters growth time vs. wavelength. $\rho_{1}>\rho_{2}$ represent the growth time of a small perturbation with a characteristic wavelength $\lambda$. If the heavy fluid lies below, i.e., $\rho_{1}<\rho_{2}$, so the growth time $\tau_{a}$ is negative and the configuration is stable for any wavelength $\lambda$ of initial perturbation. However, if the light fluid lies below, i.e., $\rho_{1}>\rho_{2}$, the constant $\tau_{a}$ is positive and the configuration is unstable for any wavelength $\lambda$ of the initial perturbation. However, there is one wavelength $\lambda_{d}$ that will present the biggest growth rate of the initial perturbation. A perturbation with this wavelength will dominate the instability. To obtain the value of $\lambda_{d}$ one must just minimize $\tau_{a}$ whose value is given by Equation (8). The graphics plotted in Figure 3 with the dimensionless parameters growth time $\left(\frac{\tau_{\mathrm{a}} \mathrm{g}\left(\rho_{1}-\rho_{2}\right) \mathrm{h}}{\mu_{1}}\right)$ vs. wavelength $\lambda_{\text {adm }}=\left(\frac{2 \pi h}{\lambda}\right)$ illustrate the behavior.

In the graphic shown in Figure 3, the minimum values of $\lambda_{\text {adm }}=\xi$ will result in lower growth time and, consequently, in the dominant wavelengths 
$\xi=\frac{2 \pi h}{\lambda_{d}} \therefore \lambda_{d}=\frac{2 \pi}{\xi} h$. To make the analysis easier

Biot and Odé (1965) defined a characteristic time $t_{c}$ that measures the required time to the initial amplitude being amplified by a factor $10^{3}$, or:

$t_{c}=3 \times \tau_{a} \ln 10$

Considering $\rho_{2}=2,200 \mathrm{~kg} / \mathrm{m}^{3}$ e $\mu_{2}=10^{17}$ Pa.s as, respectively, the density and the viscosity of a salt layer, one could analyze how the parameters affect the stability problem. The Table 1 summarizes some results.

Table 1 shows that the critical time is strongly affected by the overburden stress, proportional to the high $h$, and that higher the overburden stress is, faster the instability grows. About the relation between viscosities one can see a clear dependence between the growth time and the viscosity contrast, $\mu_{1} / \mu_{2}$. The higher the viscosity $\mu_{1}$ of the upper strata is, the higher the critical time will be, i.e., an example is the instability which rises slowly.

\subsection{Stress field}

For a bidimensional model of incompressible Newtonian fluid, the stress tensor at any point is represented by the matrix (Eq. 10):

$\vec{T}=\left[\begin{array}{cc}\sigma_{x x} & \tau_{x z} \\ \tau_{z x} & \sigma_{z z}\end{array}\right]$

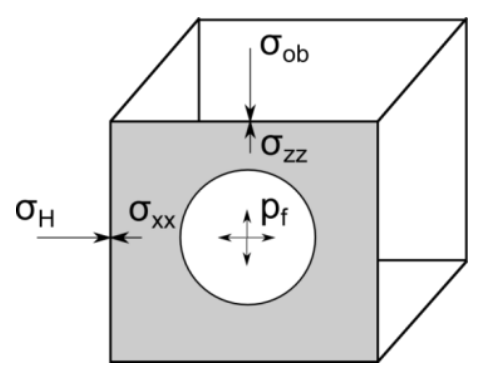

Figure 4. Scheme of the stress distribution into the bulk. Here, to achieve the force equilibrium, in the vertical direction, the overburden stress $\sigma_{\mathrm{ob}}$ must has the same intensity that the sum of the pore pressure $p_{f}$ and the vertical effective stress $\sigma_{z z}$ in the matrix rock. In the horizontal direction, the horizontal stress $\sigma_{H}$ has the same intensity as the sum of pore pressure and horizontal effective stress $\sigma_{\mathrm{xx}}$.
Table 1. Case $\rho_{1}=2,400 \mathrm{~kg} / \mathrm{m}^{3}$.

\begin{tabular}{|c|c|c|c|}
\hline$\frac{\mu_{1}}{\mu_{2}}$ & $\frac{\lambda_{d}}{h}$ & $h(\mathrm{~m})$ & $t_{c}$ (years) \\
\hline \multirow{2}{*}{1} & \multirow{3}{*}{2.57} & 2,000 & $66.17 \times 10^{3}$ \\
\cline { 3 - 4 } & & 1,000 & $132.30 \times 10^{3}$ \\
\cline { 3 - 4 } 10 & \multirow{3}{*}{3.15} & 500 & $264.70 \times 10^{3}$ \\
\hline \multirow{3}{*}{$10^{3}$} & \multirow{3}{*}{3.82} & 1,000 & $616.00 \times 103$ \\
\cline { 3 - 4 } & & 500 & $1.23 \times 10^{6}$ \\
\hline & & 2,000 & $23.93 \times 10^{6}$ \\
\hline & & 500 & $47.85 \times 10^{6}$ \\
\hline
\end{tabular}

Where:

$\tau_{x z}=\tau_{z x}=\mu\left(\frac{\partial u}{\partial z}+\frac{\partial w}{\partial x}\right)$

are the shear stress at the point,and:

$\sigma_{z z}=-p+2 \mu \frac{\partial w}{\partial z}$

is the normal tension oriented in the vertical direction, called effective tension of rock matrix (Fertil, 1981). Such tension, considering a static system, must be equal to the difference between the pore pressure and the overburden stress, $\sigma_{o b}$, which is the sum of pressure exerted by the weight of sediments and the interstitial fluid (Figure 4), i.e.:

$\sigma_{o b}=\frac{\text { sediment weight }+ \text { water weight }}{\text { area }}=p_{f}+\sigma_{z z}$

This equation was proposed by Therzaghi (1925) for unconsolidated soils. Later, it was translated into English (Therzaghi, 1943), and generalized by Biot (1941) for application on rocks:

$\sigma_{o b}=\alpha\left(p_{f}\right)+\sigma_{z z}$

Where $p_{f}$ is the formation pore pressure, 
$\alpha=1-\frac{C_{R}}{C_{B}}$ is the poroelastic constant being $C_{R}$ the rock matrix compressibility and $C_{B}$ the bulk compressibility. Normally the poroelastic constant is assumed as unit $\alpha=1$. Then,

$$
\sigma_{z z}=\sigma_{o b}-p_{f}
$$

The overburden stress depends on formation density, which varies in function of porosity:

$$
\rho_{b}=(1-\phi) \rho_{m a}+\phi \rho_{f}
$$

Where $\rho_{b}$ is the bulk density, $\rho_{m a}$ and $\rho_{f}$ are, respectively, the rock matrix density and the fluid density, and $\phi$ is the porosity or void fraction.

The overburden stress gradient is generally assumed to be equal to $1.0 \mathrm{psi} / \mathrm{ft}$, which is equivalent to an average bulk density of, approximately, $19.2 \mathrm{lbm} / \mathrm{gal}$ or $2,300 \mathrm{~kg} / \mathrm{m}^{3}$. If one wants more precision, one should consider that because the compaction of the porosity $\phi$ is, in general, an inverted function of depth, following, according to Rubey and Hubbert (1959), fairly close to the relation:

$\phi=\phi_{0} e^{-K_{\phi} z}$

Where $\phi_{0}$ is the initial porosity and $K_{\phi}$ the decay porosity constant for a specific case. In an offshore environment, it implies:

$$
\sigma_{o}=g \int_{0}^{D_{w}} \rho_{s w} d z+g \int_{D_{w}}^{D} \rho_{b} d z
$$

or

$$
\sigma_{o b}=D_{w} g \rho_{s w}+g \int_{D_{w}}^{D}\left[\rho_{m a}-\left(\rho_{m a}-\rho_{f}\right) \phi_{0} e^{-K_{\phi} z}\right] d z
$$

Where $D$ is the final depth, $D_{w}$ is the sea water depth, $\rho_{m a}$ is the matrix density and $\rho_{s w}$ is the sea water density. According to Bourgoyne et al. (1986) $D_{s}=D-D_{w}$ is defined as the depth measured of the ocean floor and the integral results in:

$$
\begin{array}{r}
\sigma_{o b}=D_{w} g \rho_{s w}+ \\
+g\left[\rho_{m a} D_{s}-\frac{\left(\rho_{m a}-\rho_{f}\right) \phi_{0}}{K_{\phi}}\left(1-e^{-K_{\phi} D_{s}}\right)\right]
\end{array}
$$

Finally,

$$
\sigma_{x x}=-p+2 \mu \frac{\partial u}{\partial x}
$$

is the normal horizontal tension in the rock matrix. Considering $p=\frac{\sigma_{z z}+\sigma_{x x}}{2}$ as the mean normal stress of compression, according to Jurgenson(1973), it corresponds to the volumetric tension over the rock matrix. Therefore, one can obtain:

$\sigma_{x x}=-\frac{\sigma_{z z}}{3}+\frac{4 \mu}{3} \frac{\partial u}{\partial x}=-\frac{\sigma_{o b}-p_{f}}{3}+\frac{4 \mu}{3} \frac{\partial u}{\partial x}$

Where the stress tensor (Eq. 10) could be written in the form:

$$
\vec{T}=\left[\begin{array}{cc}
-\frac{\sigma_{o b}-p_{f}}{3}+\frac{4 \mu}{3} \frac{\partial u}{\partial x} & \mu\left(\frac{\partial u}{\partial z}+\frac{\partial w}{\partial x}\right) \\
\mu\left(\frac{\partial u}{\partial z}+\frac{\partial w}{\partial x}\right) & \sigma_{o b}-p_{f}
\end{array}\right]
$$

\section{RESULTS AND DISCUSSIONS}

With constant stream function and the growth time it is possible to estimate the velocity fields and the stress in the interface of strata using the tensor shown in Equation 23. However, it is necessary, first, to make some considerations with the intention of adjusting the initial form of the interface surface $\eta(x, t=0)$. By the fact that this function describes the surface format in the instant when the perturbation starts to grow it is reasonable to consider it to have an harmonic shape, so $\eta(x, t=0)=\eta_{0} \cos \left(k x+\varphi_{0}\right)$.

Observing a diapir, through seismic sections, one can measure the distance between the top of the dome and the base. These measurements allow 
one to estimate its actual amplitude $\eta\left(0, t_{F}\right)$, where $t_{F}$ is the time elapsed from the instant at which the instability starts until the final time.

In the case in consideration, the top of the salt dome is in a depth of approximately $4,300 \mathrm{~m}$ and reaches a final depth of approximately $6,000 \mathrm{~m}$, totaling $1,700 \mathrm{~m}$ or an amplitude of $850 \mathrm{~m}$. This amplitude imposes the condition $h=5,150 \mathrm{~m}$ to the thickness of the sediment's layer. With this information, one can determine the dominant wavelength of perturbations:

$\lambda_{d}=19677.6 \mathrm{~m}$

Assuming that $\mu_{\text {sal }}=10^{17}$ Pa.s and $\mu_{\text {sed }}=10^{20}$ Pa.s the growth time is:

$\tau_{a}=4.66 \times 10^{13} \mathrm{~s}=1.48 \times 10^{6}$ years

and the critical time $t_{c}=10.02 \times 10^{6}$ years.

It is noteworthy that, according to Drazin (2002), the interval time defined by $\tau_{a}$ specifies the limit to the linear approximation made in the hydrodynamic instability theory. Whereas, for time intervals with magnitude greater than that a nonlinear analysis is necessary because the order terms can no longer be neglected due to the great deformations imposed to the fluid, in this case, the salt.
For a given rate of sedimentation, one can estimate the instant when the instability starts, that is, the instant in which $\rho_{\text {sal }}=\rho_{b}=2,200 \mathrm{~kg} / \mathrm{m}^{3}=$ $18.4 \mathrm{lb} / \mathrm{gal}$. Based on the curve shown in Figure 5, obtained from a drilling in Campos Basin, one can determine the overburden stress through the relation:

$$
\frac{\sigma_{o b}}{D}=G S
$$

This relationship results in the values shown in the graphics at Figure 6.

For this particular case, the density function (Eq. 16) assumes the form:

$\rho_{b}=\left(1-0.74 e^{-0.00125 z}\right) 2,400+0.74 e^{-0.00125 z} 1,030$

The solution for $\rho_{b}=\rho_{\text {salt }}=2,200 \mathrm{~kg}$ is:

$$
z=\frac{\ln \frac{(2,200-2,400)}{0,74 \times(1,030-2,400)}}{-0.00125}=1,300 \mathrm{~m}
$$

Considering a rate of sedimentation of $20 \times 10^{-3}$ $\mathrm{cm} /$ years, it would be necessary a 6.5 million-year period for the instability to begin. Whereas the sediment layer has been deposited in the upper Albian, one can define $t_{F}=10 \mathrm{Ma}-6.5 \mathrm{Ma}=93.5 \mathrm{Ma}$ as the development time for the salt dome.

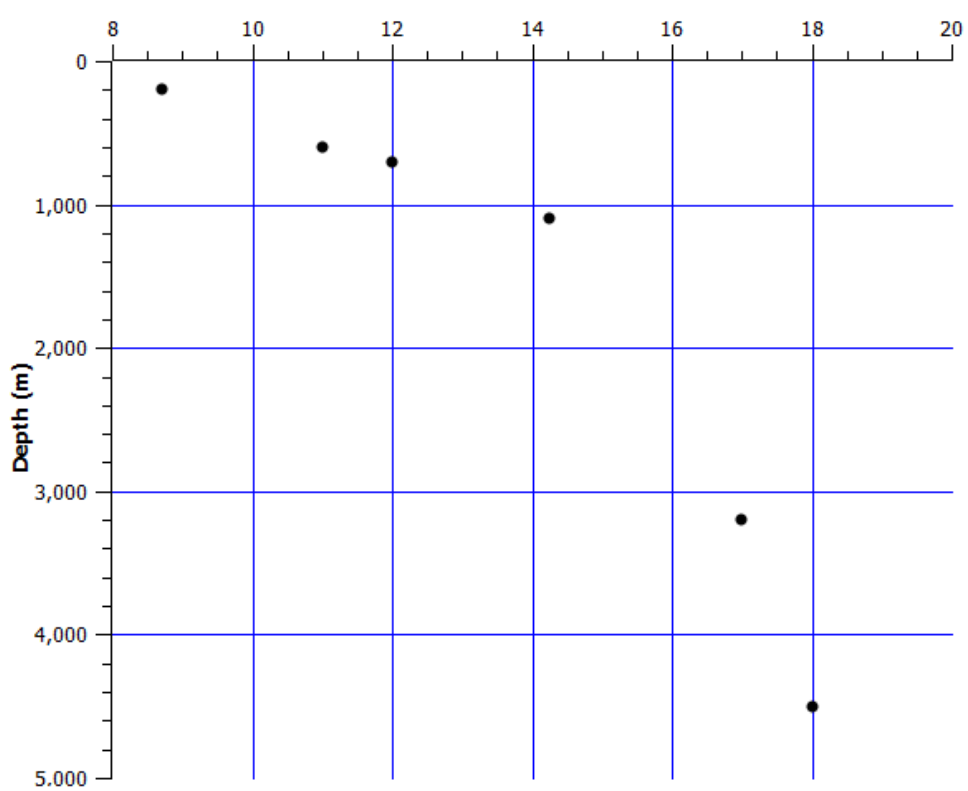

Figure 5. Overburden stress gradient in a well next to a salt dome at Campos Basin. 


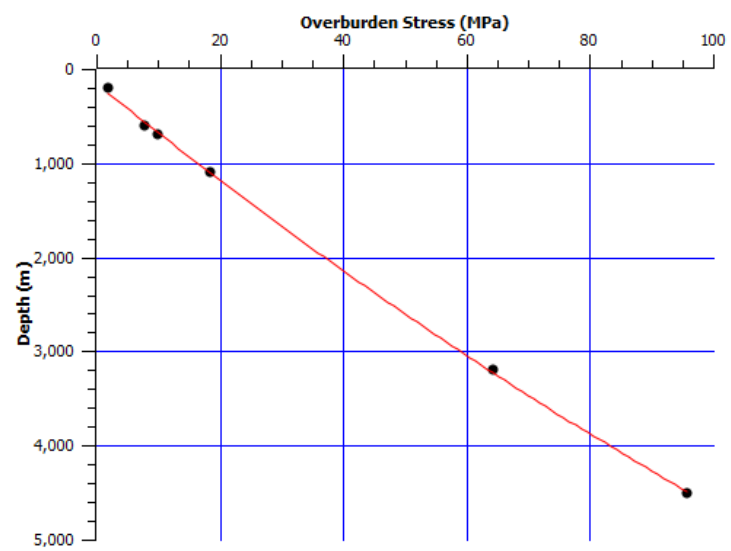

Figure 6. Overburden stress in a well next to a salt dome at Campo Basin. With a regression, imposing a relation like the one described by Equation 20, one can find $K_{\phi}=1.25 \times 10^{-3} \mathrm{~m}^{-1}$ and $\phi_{0}=0.74$ with $\rho_{\mathrm{sw}}=\rho_{\mathrm{f}}=1,030 \mathrm{~kg} / \mathrm{m}^{3}, \rho_{m a}=2,400 \mathrm{~kg} / \mathrm{m}^{3}$ and $\mathrm{D}_{\mathrm{W}}=$ $200 \mathrm{~m}$.

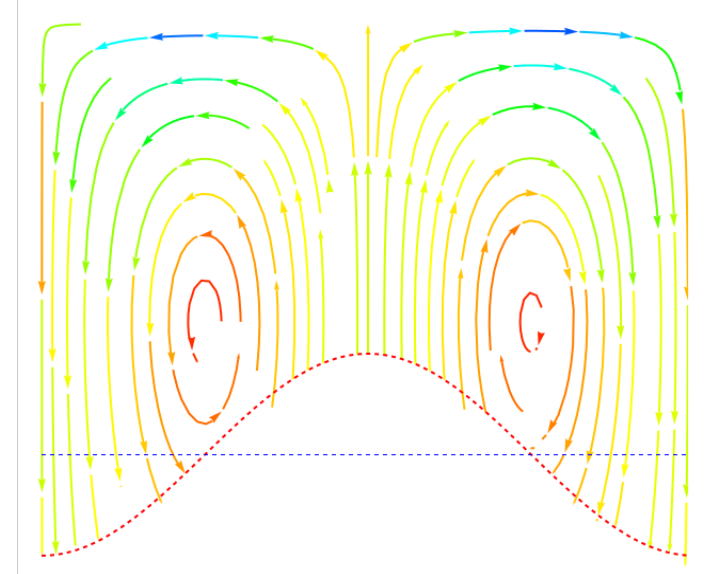

Figure 7. Velocity field. One can see the stream lines tangent to the velocity vector in each point.

Having the $t_{F}$ value at hand, one can determine the parameter $\eta_{0}=\eta\left(x, t_{F}\right) e^{-t_{F} / \tau_{a}}=2.93 \times 10^{-25} \mathrm{~m}$ and the function that describes the shape of the surface between the two layers as:

$\eta(x, t)=2.93 \times 10^{-25} e^{6.76 \times 10^{-7} t} \cos (0.00032 x)$

with $[\mathrm{t}]=$ years and $[\mathrm{x}]=\mathrm{m}$.

The Figure 7 shows the velocity field, obtained with the stream function.

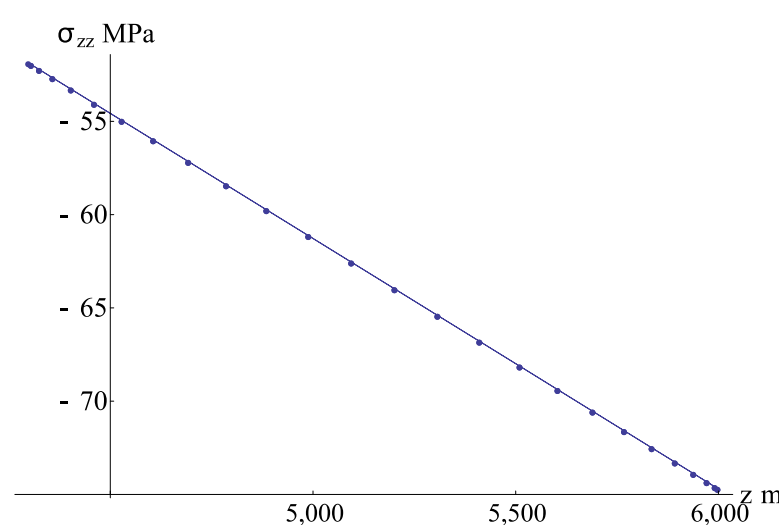

Figure 8. Vertical effective tension on the separation surface at a depth $z$.

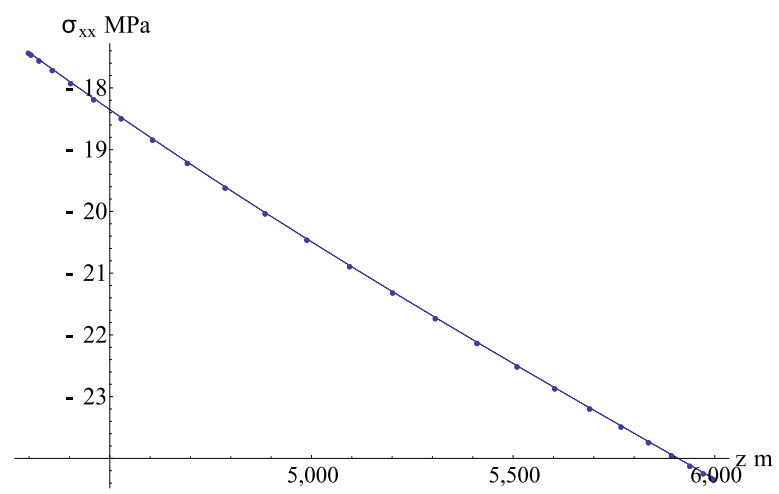

Figure 9. The horizontal stress on the separation surface as function of depth $z$.

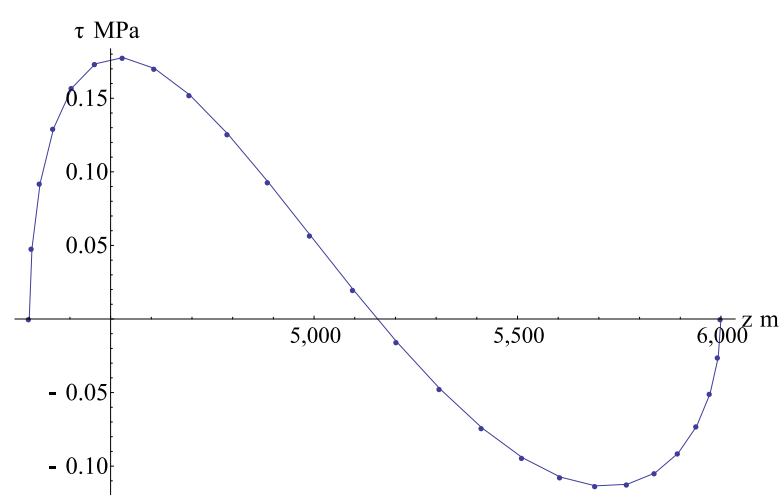

Figure 10. Shear stress on the separation surface as function of depth $z$.

Writing the stress tensor (Eq. 23) and evaluating the stresses for points on the separation surface along the dome, one can obtain the following results: 


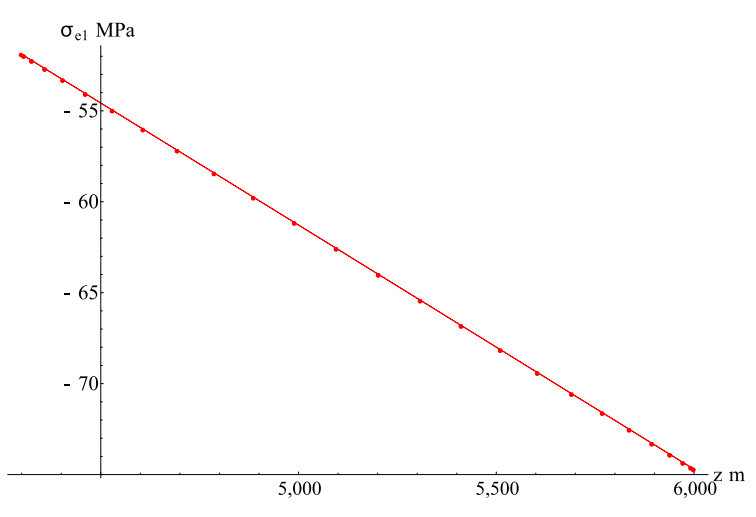

Figure 11. The maximum normal stress on the surface of separation as function of depth $z$.

- The vertical tension is equal to the difference between the overburden stress and the pore pressure (Figure 8).

- Shear stresses are induced by the salt piercing into the formation above (Figures 9 and 10). The model predicts, for the parameters adopted, shear stresses up to $150 \mathrm{kPa}$ in regions near to the top of the salt dome.

- Due to shear stress, it becomes evident that the components of the tensor $\vec{T}$, written for a coordinate system whose $z$ axis coincides with the vertical direction, no longer represent the principal direction. To find new directions, simply determine the eigenvalues (maximum normal stresses $\sigma_{e 1}$ and $\sigma_{e 2}<\sigma_{e 1}$ ) and the eigenvectors (principal directions $e 1$ and $e 2$ ) of the tensor at any point. The (Figure 11) shows the eigenvalues $\sigma_{1}$ evaluated for the region of the separation surface between the layers.

\subsection{Pore pressure effects}

In a normal situation, the pore pressure gradient $p_{f} / D$ will follow, approximately, the water pressure gradient, then:

$$
\frac{p_{f}}{D}=\rho_{w} g
$$

So,

$$
p_{f}=\rho_{w} g D
$$

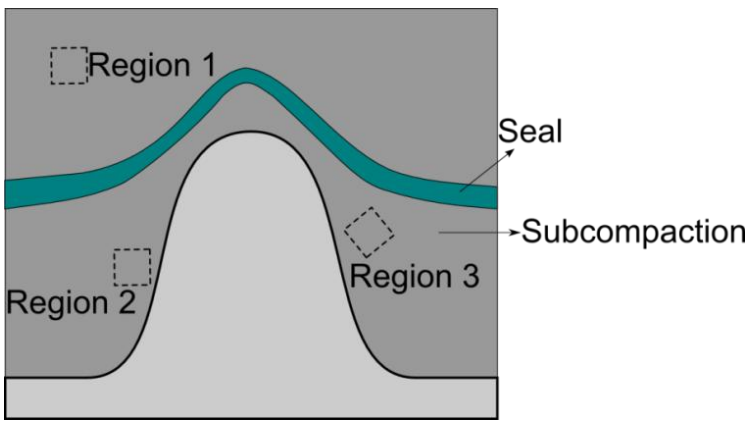

Figure 12. Representation of a salt dome piercening.
Region 1

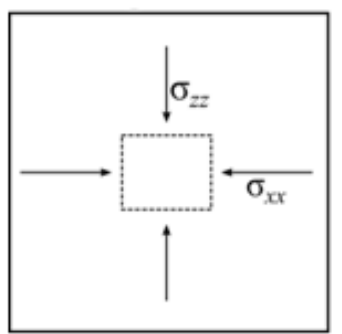

(a)
Region 2

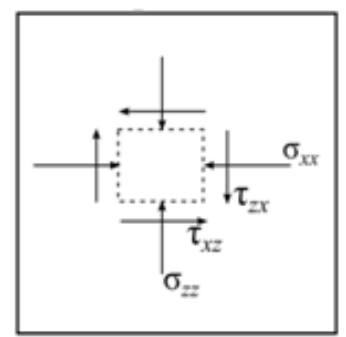

(b)

\section{Region 3}

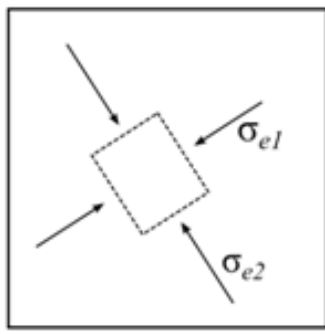

(c)

Figure 13. Distinct regions of a rock formation pierced by a salt dome and it's resulting tension field. (a) stress in region 1 , not influenced by the salt dome. The vertical direction coincides with one of the principal directions; (b) stresses in region 2, strongly influenced by the salt dome. The vertical direction does not coincide anymore with one of the principal directions, consequently, the shear stress changes due to the salt piercing and (c) stresses in region 3 , are influenced strongly by the salt dome. Due to an axis rotation, only normal stresses are acting, it means that the directions shown are the principal directions. 


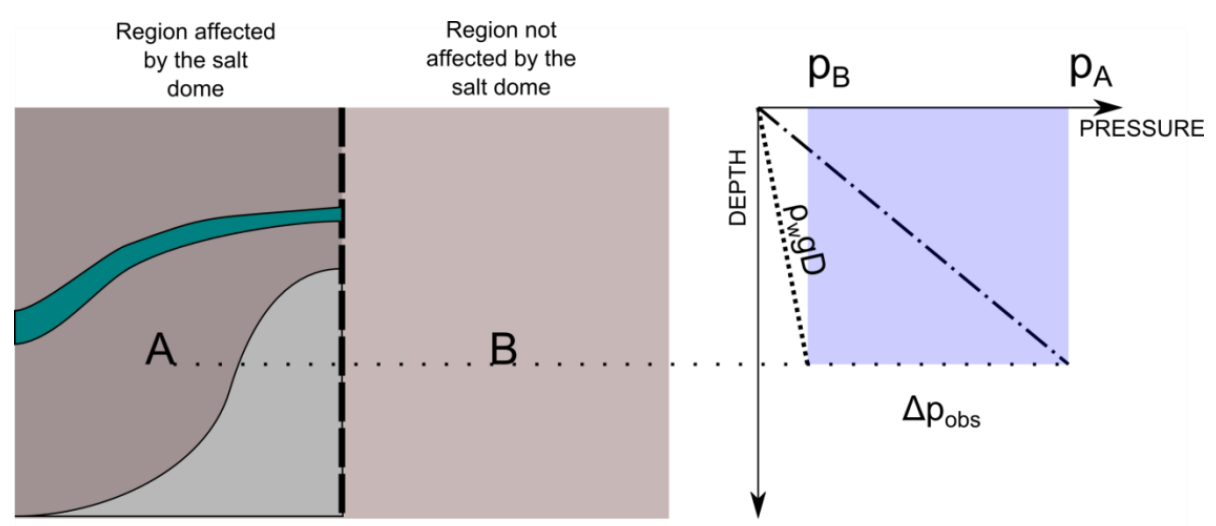

Figure 14. At $B$, one can observe the fluid pressure expected (hydrostatic pressure). At point $A$, the fluid pressure is changed by the salt dome. The difference $\Delta p_{o b s}$ must be equal to the measure increase.

The hydrostatic pressure is affected by some factor such as the salt concentration, the gas dissolution, and the temperature gradients. Typical values of hydrostatic gradient are $0.433 \mathrm{psi} / \mathrm{ft}$ for fresh water and $0.465 \mathrm{psi} / \mathrm{ft}$ for salt water (Fertil, 1981). If there is a restriction to the flow of the interstitial fluid through the rock pores, it could be followed by a pore pressure buildup and, consequently, one would observe a subcompation region.

It is fundamental to observe that in normal situations the vertical direction is considered one of the principal directions of tension field in a rock formation, being $\sigma_{z z}$ one of the principal tensions, but, eventually, this could not occur. Factors like diapirism may be interfere in the tension field and change such directions. To find the principal

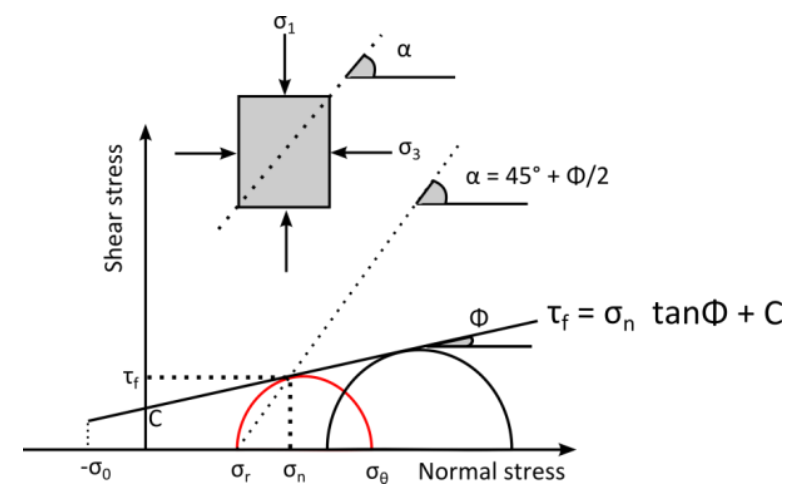

Figure 15. Morh-Coulomb fail criterion, widely used for brittle materials. Where $\alpha$ indicates the fail plane angle by shear, $\phi$ is the angle of internal friction, and $C$ is the cohesion of the rock sample. directions at any point $\left(\sigma_{e 1}\right.$ and $\left.\sigma_{e 2}\right)$, it is necessary to promote an axis rotation. To perform this turn, find the eigenvector of the stress tensor. This situation is shown in Figures 12 and 13.

It is possible to estimate the pore pressure increase due to the dome piercing by determining the great normal tension $\sigma_{e 1}$ and comparing to normal overburden stress expected $\sigma_{o b}$ in the same depth. The difference between these values will be supported by the interstitial fluid, changing the expected pore pressure evaluated by the expression (31). This idea is illustrated in Figure 14.

With the increase in the pore pressure there will be risks of eventual kicks during the well drilling phase.

\subsection{Effects over the casing setting}

One of the criteria to settle the casing is the operational window, i.e., the difference between the pore pressure or the collapse pressure (whichever was larger) and the fracture tension. To drill safely it is necessary to protect formation areas, regions where the operation window is reduced, to keep the well stability, to avoid lost circulation, landslides, or hydraulic fractures.

The fracture stress will be defined by any particular criterion. Among the criteria used, the Mohr-Coulomb criterion is one of the most widely used in petroleum industry. This criterion defines the failure stress state through the tangent line of the Mohr circles for which a rock sample has shown failure in a previous test (Figure 15). 
The Equation 32 defines the Morh circles:

$$
\left(\sigma-\frac{\sigma_{1}+\sigma_{2}}{2}\right)^{2}+\tau^{2}=\left(\frac{\sigma_{1}-\sigma_{2}}{2}\right)^{2}+\tau_{12}^{2}
$$

Where the stress state depends of principal stress $\sigma_{1}$ and $\sigma_{2}$ applied over the body.

Nowadays, it is believed that the in situ stress is one of the principal causes of well instability. In the case that a well is drilled in an unfavorable direction, imposing great stress in its walls, there are great chances of the well becoming unstable. Considering the need for stability, whenever exists great in situ stress perturbations, such as the case discussed in this work, it is advisable to proceed with a directional drilling.

\subsection{Effects over casing}

With the raise of the diaper, slip of materials occurs to the center of the salt dome. If the well has been drilled through, a salt formation it will be under deviatoric stresses due to this movement.

As pointed out in the sensitivity analysis shown in Table 1, the lower viscosity of the upper layer is if compared to the bottom layer, the faster the growth of instability will be. If the existent layers have different mobilities, i.e. the layers have different viscosities, a differential slipping of such layers could happen. It amplifies the shear stress over the casing, causing a guillotine effect, which may lead to a casing collapse.

\section{CONCLUSIONS}

Analytical models are very important because they improve the comprehension about the physical mechanisms that control the phenomenon of a salt dome evolution. The models enable, as a quick form, ones to estimate several important parameters in the drilling and completion of an oil well process. It also provides the best approximations for initial values in numerical simulations, accelerating the convergence. However, to reach a better precision in the results, it is necessary to use numerical methods, because the analysis becomes very difficult due to the great level of detail necessary to evaluate the flow pattern and stresses field that are useful and trustful. As shown in the determination of shear stress, the highest value reached had a magnitude of $1.7 \times 10^{5} \mathrm{~Pa} \approx 24.65 \mathrm{psi}$, insufficient to justify greats differences between the principal directions and the vertical direction observed near the salt domes. The present model determined, for points near the salt dome, almost the same values for the vertical stress and principal stress, taking into account that, in this region, a great difference in values is expected because of the influence of the diapir. However, based on this model it became possible to develop another model, more comprehensive and representative.

This model considers only the linear phase of RT instability and, therefore, can describe the growth of a diapir only in the initial stage. This is relevant because, in the course of time, other instabilities as, for example, the Kelvin-Helmholtz exhibit an important role over the final format of the dome and, notwithstanding, nonlinearities should be considered. Fault-effects and redistribution of sediments over the free surface above the sediment layer, as well as differential overburden, should be looked upon, according to Schultz-ela et al. (1993), Poliakov et al. (1996), and Poliakov et al. (1993).

\section{REFERENCES}

Barton, D. C. Mechanics of formation of salt domes with special reference to Gulf Coast salt domes of Texas an Louisiana. American Petroleum and Geology Bulletin, v. 17, p. 1025-1083, 1933.

Biot, M. A. General Theory of ThreeDimensional Consolidation. Journal of Applied Physics, v. 12, p. 155-165, 1941. http://dx.doi.org/10.1063/1.1712886

Biot, M. A. Stability of Multilayered Continua Including the Effect of Gravity and Viscoelasticity. J. Franklin Institute, v. 276, p. 231-252, 1963. http://dx.doi.org/10.1016/0016-0032(63)90385-5

Biot, M. A. Theory of Stability of Multilayered Continua in Infinite Anisotropic Elasticity. J. Franklin Institute, v. 276, p. 128-153, 1963. http://dx.doi.org/10.1016/0016-0032(63)90416-2 
Biot, M. A.; Ode, H. Theory of Gravity Instability with Variable Overburden and Compaction. Geophysics, v. 30(2), p. 213-227, 1965. http://dx.doi.org/10.1190/1.1439558

Bourgoyne, A. T.; Milheim, K. K.; Chenevert, M. E.; YOUNG Jr., F. S. Applied Drilling Engineering. [S.I.]: SPE TextBook Series, v. 2, 1986. 502 p.

Drazin, P. G. Introduction to Hydrodynamic Stability. [S.I.]: Cambridge University Press, 2002. ISBN ISBN: 9780521009652 LCCN: 2002025690.

Fertil, W. H. Abnormal Formation pressures. Second. ed. [S.I.]: Elsivier, v. 2, 1981. 382 p.

Jackson, M. P. A. Retrospective Salt tectonics. In: Jackson, M. P. A.; Roberts, D. G.; Snelson, S. Salt Tectonics: A Global Perspective. [S.I.]: The American Association of Petroleum Geologists, v. 65, 1995.

Jurgenson, L. Perplexity caused by the hydrostatic stress. Geotechnique, v. 23, p. 448-450, 1973. http://dx.doi.org/10.1680/geot.1973.23.3.448

Mohriak, W.; Szatmari, P. Tectônica do Sal. In: Mohriak, W.; Szatmari, P.; Anjos, S. M. C. Sal: Geologia e Tectônica. [S.I.]: Editora Beca, 2008. p. 93-164.

Poliakov, A. N. B.; van Balen, R.; Podladchicov, Y.; Daudre, B.; Cloethingh, S.; Talbot, C. J. Numerical analysis of how sedimentation and redistribution of superficial sediments affects diapirism. Tectonophysics, v. 226, p. 199-216, 1993. http://dx.doi.org/10.1016/0040-1951(93)90118-4

Poliakov, A. N. B.; Podladchicov, Y.; Sawson, E. Ch.; TALBOT, C. J. Salt diapirism with simultaneous brittle faulting and viscous flow. Geological Society Special Publication, v. 100, p. 291-302, 1996.

Rayleigh, L. Investigation of the Character of the Equilibrium of an Incompressible Heavy Fluid of Variable Density. Proceedings of London Mathematical Society, v. 14, p. 170-177, 1883.
Rocha, L. A. S.; Azevedo, C. T. Projetos de poços de petróleo. 2. ed. [S.I.]: Editora Interciencia, 2009.

Rubey, W. W.; Hubbert, M. K. Role of Fluid Pressure in Mechanics of Overthrust Faulting. GSA Bull, v. 70, p. 115, 1959. http://dx.doi.org/10.1130/00167606(1959)70[167:ROFPIM]2.0.CO;2

Schultz-Ela, D. D.; Jachson, M. P. A.; Vendeville, B. C. Mechanics of active salt diapirism. Tectonophysics, v. 228, p. 275-312, 1993. http://dx.doi.org/10.1016/0040-1951(93)90345-K

Stille, $H$. The upthrust of the salt masses of Germany. American Association of GeologistsBulletin, v. 9, p. 417-441, 1925.

Taylor, G. The Instability of Liquid Surfaces when Accelerated in a Direction Perpendicular to their Planes. Proc. Royal Soc. A, n. 201, p. 192-196, 1950.

Therzaghi, K. Erbdaumechanik auf Bodenphysikalischer Grundlage. Leipzig F. Deuticke. [S.I.]: [s.n.]. 1925.

Therzaghi, K. Theoretical Soil Mechanics. [S.I.]: John Wiley \\& Sons, 1943.

Turcotte, D. L.; Schubert, G. Geodynamics: Applications of Continuun Physics to Geological Problems. 1st. ed. New York: John Wiley $\backslash \&$ Sons, 1982. ISBN ISBN: 0-471-06018-6.

Vendeville, B. C.; Jackson, M. P. A. The rise of diapirs during thin-skinned extension. Marine and Petroleum Geology, v. 9, p. 331-353, 1992. http://dx.doi.org/10.1016/0264-8172(92)90047-l

Ville, L. Notice geologique sur les salines des Zahrez et les gites de sel gemme de Rang el Melah et d' Ain Hadjera (Algerie). Annales de Mines, v. 13, p. 351-334, 1856. 